\title{
Prognosis Prediction Using Therapeutic Agreement of Video Conference-Delivered Cognitive Behavioral Therapy: Retrospective Secondary Analysis of a Single-Arm Pilot Trial
}

Kazuki Matsumoto ${ }^{1}, \mathrm{PhD}$; Tokiko Yoshida ${ }^{1}, \mathrm{PhD}$; Sayo Hamatani ${ }^{1,2}, \mathrm{PhD}$; Chihiro Sutoh $^{3}, \mathrm{MD}$, PhD; Yoshiyuki Hirano $^{1}, \mathrm{PhD}$; Eiji Shimizu ${ }^{1,3}, \mathrm{MD}, \mathrm{PhD}$

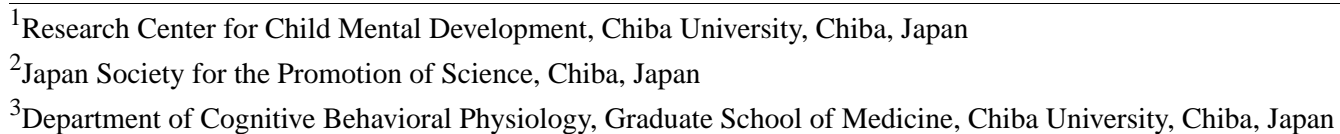

\section{Corresponding Author:}

Kazuki Matsumoto, $\mathrm{PhD}$

Research Center for Child Mental Development

Chiba University

1-8-1, Inohana, Chuo-ku

Chiba, 2608670

Japan

Phone: 81080432262975

Email: axpa0219@chiba-u.jp

\section{Abstract}

Background: The therapist-patient therapeutic alliance is known to be an important factor in cognitive behavioral therapy (CBT). However, findings by previous studies for obsessive-compulsive disorder (OCD), panic disorder (PD), and social anxiety disorder (SAD) have not been consistent regarding whether this alliance provides symptomatic improvements.

Objective: This study investigated predictors of symptom improvement in patients receiving CBT via video conferencing.

Methods: A total of 29 patients who participated in a previous clinical trial were recruited for the current study. Therapeutic alliance and clinical background in patients with OCD, PD, and SAD were measured at first session or the eighth session, which were calculated by multiple regression analyses to estimate the impact on therapeutic response percentage change.

Results: The multiple regression analyses showed that, among the independent variables, only patients' agreement in the therapeutic alliance remained viable, as other variables were a best fit for the excluded model $(P=.002)$. The results show that patients' agreement on therapeutic goals and tasks explains the prognosis, as the normalization factor beta was 0.54 (SE 32.73; 95\% CI 1.23-5.17; $P=.002$ ) and the adjusted $R^{2}$ was .266.

Conclusions: Patients' agreement on therapeutic goals and tasks predicts improvement after CBT via video conferencing.

Trial Registration: UMIN Clinical Trial Repository UMIN000026609; https://tinyurl.com/ye6dcbwt

(JMIR Ment Health 2019;6(11):e15747) doi: $\underline{10.2196 / 15747}$

\section{KEYWORDS}

therapeutic alliance; cognitive behavioral therapy; obsessive-compulsive disorder; panic disorder; social anxiety disorder; video conferencing

\section{Introduction}

One of the principles of cognitive behavioral therapy (CBT) is the therapist-patient therapeutic relationship [1], which is consistently important from the initial session of therapy to its last stage [2-4]. The therapist and patient collaboratively work together over time on the patient's therapeutic goal of achieving symptomatic relief. However, the results of previous studies have not been consistent about whether the therapeutic relationship in CBT affects symptomatic outcomes [4,5].

Two systematic reviews, including a meta-analysis of depression, have shown moderate correlations between the therapeutic relationship (assessed through the Working Alliance Inventory [WAI] scale) and symptomatic outcomes [6,7]. These 
previous studies, conducted by correlation analysis, could not explain the causal relationship. Further, the causal relationship between the therapeutic relationship and its outcomes was discussed by retrospective observational studies in clinical trials, but the results were not consistent. For example, in CBT used for the treatment of panic disorder (PD), it has been suggested that a high rate on the WAI-Short Form (WAI-SF) is an important factor for a patient's symptomatic improvements [8]; however, regarding CBT for the treatment of obsessive-compulsive disorder (OCD), it has been reported that scores on the WAI-SF did not affect the patient's symptomatic improvements [9]. Furthermore, in a recent study of the WAI-SF [10], the two factors of therapeutic relationship and patient agreement were analyzed. It was found that a patient's strong agreement with CBT tasks predicted symptomatic improvements. In the past, the WAI-SF was supposed to have three factors: development of an affective bond, agreement with the task, and agreement with the goal between the therapist and patient [10]. CBT requires a restructuring of dysfunctional cognitions and behaviors that a patient has formed over many years; thus, it seems logical to infer that patients' agreement may have an impact on symptomatic improvements.

Use of the internet has spread worldwide and it has seen use by 4.536 million people $(58.8 \%)$ globally as of June 2019 [11,12]. Internet-based CBT was created as a result of the incorporation of programming technology into CBT, and it has demonstrated effective results through its therapeutic processes by creating symptomatic improvements [13,14]. While the telemedicine approach is the most like traditional face-to-face treatment, previous research on video conference-delivered CBT has been limited compared to normal internet-based CBT [15-20]. A systematic review revealed that the therapeutic relationship is maintained at sufficiently high levels when using video conferencing [21]. However, to the best of our knowledge, the influence of the therapist-patient relationship developed through video conference-delivered CBT on patients' symptomatic improvement has not yet been investigated [22]. In the current study, we investigated predictors for improvement among patients after they received CBT via video conferencing.

\section{Methods}

\section{Study Design and Participants}

This study utilized secondary data analysis with data from a previous clinical, pilot, single-arm trial on video conference-delivered CBT, using Cisco WebEX as the video conferencing system [19]. A total of 29 Japanese adult participants (mean age 35.5 years old; SD 9.2), 5 of whom were male and 24 of whom were female, completed the intervention. We hypothesized that therapist-patient agreement on therapeutic goals and challenges would predict patient prognosis. Baseline data was used exploratorily and analyzed through a series of statistical analyses.

\section{Measures}

To assess the severity of symptoms as the primary outcome, we evaluated each mental health disorder of interest using a corresponding scale: OCD was assessed through the Yale-Brown Obsessive-Compulsive Scale (Y-BOCS); PD was assessed through the Panic Disorder Severity Scale (PDSS); and social anxiety disorder (SAD) was assessed through the Liebowitz Social Anxiety Scale (LSAS) [23-25]. Furthermore, depression was assessed through the Patient Health Questionnaire-9 (PHQ-9) [26], general anxiety was assessed through the Generalized Anxiety Disorder-7 (GAD-7) scale [27], and the therapist-patient therapeutic relationship was assessed through the WAI-SF [2]. Regarding the WAI-SF sub-scales, the agreement score was composed of the total scores of items 1 , $2,6,8,11$, and 12 , and the bond score was composed of the total scores of items 3, 5, 7, and 9 [10].

In our previous clinical trial, CBT was evaluated at the first, eighth, and sixteenth session [20], but the therapeutic alliance per WAI-SF [2] was set as a predictor in the eighth session. This is because it is anticipated that a well-established treatment relationship in the first half will affect the patient's engagement with the second half of the challenge (mostly with exposure). Depressive symptoms in PHQ-9 and general anxiety in GAD-7 at baseline (first session) were also set as predictors.

\section{Statistical Analysis}

The statistical analysis was performed using SPSS Statistics, version 24.00 (IBM, Armonk, New York, United States). First, Spearman correlation analysis was performed between the treatment response percentage change and the score in each scale (WAI-SF total, PHQ-9, GAD-7), or the subscales of WAI-SF (agreement, bond). Second, to investigate the predictive effects that the patients' backgrounds at pretreatment may have had on the treatment response change post treatment, a series of multiple regression analyses were performed. The treatment response percentage change was set as a dependent variable in multiple regression analyses. Variables were entered for analysis in a multivariate model by the forward selection stepwise procedure $(F<0.05$ as inclusion and $F \geq 0.10$ as exclusion). Multicollinearity was measured by variance inflation factors (VIF) and tolerance. If the VIF value exceeded 4.0, or by tolerance was less than 0.2 , then there was a problem with multicollinearity [28]. We excluded WAI-SF's total scores because VIF was 13.09. The treatment response percentage change was calculated by dividing the total pretreatment score with the score difference between Session 1 and Session 16. The treatment response percentage change in this study was the decline in baseline Y-BOCS, PDSS, or LSAS score. The degree of treatment response percentage change was analyzed as a continuous variable and calculated as follows:

$$
\frac{\text { (Y-BOCS, PDSS, or LSAS pre-Y-BOCS, PDSS, or LSAS post) }}{\text { YBOCS, PDSS, or LSAS pre }} \times
$$

\section{Results}

Agreement, bond, and the total score of the WAI-SF showed a significant correlation with the response percentage change as a result of correlation analysis, including Bonferroni correction (Table 1). Multiple regression analyses showed that, within the independent variables only patient agreement remained, with the other variables a better fit for the excluded model (beta $=.54$; Adjusted $R^{2}=.266$; SE $32.73 ; 95 \%$ CI 1.23-5.17; $P=.002$ ). 
Table 1. Correlation relationship between response percentage change and the patient's background/symptoms.

\begin{tabular}{|c|c|c|c|}
\hline Variable & Response percentage change $(r)$ & $P$ value & $P$ value after Bonferroni correction \\
\hline Patient agreement & .681 & $<.001$ & .005 \\
\hline Bond & .476 & .009 & .05 \\
\hline WAI-SF ${ }^{\mathrm{a}}$ total & .569 & .001 & .005 \\
\hline PHQ-9 ${ }^{b}$ & -.228 & .23 & $>.99$ \\
\hline GAD- $7^{\mathrm{c}}$ & -.292 & .12 & .60 \\
\hline
\end{tabular}

${ }^{\mathrm{a}}$ WAI-SF: Working Alliance Inventory-Short Form.

${ }^{\mathrm{b}} \mathrm{PHQ}-9$ : Patient Health Questionnaire-9.

${ }^{\mathrm{c}}$ GAD-7: Generalized Anxiety Disorder-7.

Using $\mathrm{G}^{*}$ power 3.1 [29] for power analysis, power (1-beta error probability) was calculated to be 0.88 (effect size $f^{2}=.36$; alpha error probability=.05; sample size=29), and the number of predictors was one.

\section{Discussion}

\section{Primary Findings}

The hypothesis of this study was that agreement on therapeutic goals and challenges predicts a patient's prognosis. We performed multiple regression analyses on the variables that were significantly correlated, but only the explanatory model using the patient agreement variable from the WAI was the best fit. The results suggested that patients' agreement with the set goals and tasks during the middle stage of CBT predicted symptomatic improvement.

These results are consistent with a previous study, which provides evidence that the therapist-patient therapeutic relationship is important to symptomatic improvements in the middle to late stages of therapy [4,7]. Conversely, the results of a meta-analysis of guided, internet-based CBT (except by video conferencing) suggested that the therapeutic alliance is not important to the improvement of anxiety [5]. It is interesting that the results of the current research contrast with these results from a previous study, indicating that perhaps patients who do not agree with treatment drop out early. Thus, the therapist-patient therapeutic treatment alliance in internet-based CBT may not be relevant to the therapeutic response. The total WAI score was associated with symptomatic improvements

\section{Acknowledgments}

This study was supported by the Japan Society for the Promotion of Science KAKENHI Grant-in-Aid for Scientific Research C, Grant Number 18K03130.

\section{Authors' Contributions}

KM contributed to the implementation and planning of the study and the writing of papers. TY contributed to the presentation of research results. SH contributed to the statistical analysis. $\mathrm{CH}$ contributed to the conduct of the study. YH contributed to the presentation of the research results and the development of thesis. ES contributed to the overall examination supervision and the development of the thesis.

\section{Conflicts of Interest}

None declared.

when the treatment was tailored specifically to the patient's condition during internet-based CBT [6]. Results from this prior research provided important knowledge on future directions CBT could take using the internet. Specifically, it is essential to adhere to the content of basic CBT skill sets [30]. Hence, we can infer that the therapist's work in implementing a personalized therapy may result in the patient's agreement with the therapeutic goals and tasks. Furthermore, this study's results did not identify a pretreatment predictor, consistent with previous studies of depression [31].

\section{Limitations}

First, this study had a small sample size, so future studies with a more significant sample size are needed. Second, factors affecting treatment responsiveness may be influenced by the quality of CBT, which can be assessed using a cognitive therapy scale, as well as a patient's background and their relationship with the therapist [32,33]. This study does not assess quality of treatment, patient background, or relationship with the therapist, therefore, further studies exploring this aspect of the treatment are needed. Finally, this study was a secondary analysis of a single-arm pilot study.

\section{Conclusions}

Our results suggest that patients' agreement with therapeutic tasks and goals predicts an improvement after intervention with video conference-delivered CBT. To the best of our knowledge, this is the first published evidence of this phenomenon. Therapists in the video conference-delivered CBT field should seek ways to apply tasks and goals that are tailored specifically to each patient's condition. 


\section{References}

1. Beck JS. Cognitive therapy: Basics and beyond. 1st edition. New York City, New York: The Guilford Press; 1995.

2. Raue PJ, Goldfried MR, Barkham M. The therapeutic alliance in psychodynamic-interpersonal and cognitive-behavioral therapy. J Consult Clin Psychol 1997 Aug;65(4):582-587. [doi: 10.1037//0022-006x.65.4.582] [Medline: 9256559]

3. Martin DJ, Garske JP, Davis MK. Relation of the therapeutic alliance with outcome and other variables: a meta-analytic review. J Consult Clin Psychol 2000 Jun;68(3):438-450. [Medline: 10883561]

4. Horvath AO, Del Re AC, Flückiger C, Symonds D. Alliance in individual psychotherapy. Psychotherapy (Chic) 2011 Mar;48(1):9-16. [doi: 10.1037/a0022186] [Medline: 21401269]

5. Andersson G, Paxling B, Wiwe M, Vernmark K, Felix CB, Lundborg L, et al. Therapeutic alliance in guided internet-delivered cognitive behavioural treatment of depression, generalized anxiety disorder and social anxiety disorder. Behav Res Ther 2012 Sep;50(9):544-550. [doi: 10.1016/j.brat.2012.05.003] [Medline: 22728647]

6. Bergman Nordgren L, Carlbring P, Linna E, Andersson G. Role of the working alliance on treatment outcome in tailored internet-based cognitive behavioural therapy for anxiety disorders: randomized controlled pilot trial. JMIR Res Protoc 2013 Jan 18;2(1):e4 [FREE Full text] [doi: 10.2196/resprot.2292] [Medline: 23612437]

7. Cameron SK, Rodgers J, Dagnan D. The relationship between the therapeutic alliance and clinical outcomes in cognitive behaviour therapy for adults with depression: A meta-analytic review. Clin Psychol Psychother 2018 May;25(3):446-456. [doi: 10.1002/cpp.2180] [Medline: 29484770]

8. Huppert JD, Kivity Y, Barlow DH, Gorman JM, Shear MK, Woods SW. Therapist effects and the outcome-alliance correlation in cognitive behavioral therapy for panic disorder with agoraphobia. Behav Res Ther 2014 Jan;52:26-34 [FREE Full text] [doi: 10.1016/j.brat.2013.11.001] [Medline: 24275067]

9. Wheaton MG, Huppert JD, Foa EB, Simpson HB. How important is therapeutic alliance in treating obsessive-compulsive disorder with exposure and response prevention? An empirical report. Clin Neuropsych: J Treat Eval 2016;13(6):88-93 [FREE Full text]

10. Santirso FA, Martín-Fernández M, Lila M, Gracia E, Terreros E. Validation of the Working Alliance Inventory-Observer Short Version with male intimate partner violence offenders. Int J Clin Health Psychol 2018;18(2):152-161 [FREE Full text] [doi: 10.1016/j.ijchp.2018.02.003] [Medline: 30487920]

11. Ministry of Internal Affairs and Communications. WHITE PAPER Information and Communications in Japan 2018 URL: http://www.soumu.go.jp/johotsusintokei/whitepaper/h30.html [accessed 2019-09-06]

12. Miniwatts Marketing Group. Internet World Stats. Internet Growth Statistics URL: https://www.internetworldstats.com/ emarketing.htm [accessed 2019-09-06]

13. Bordin ES. The generalizability of the psychoanalytic concept of the working alliance. Psychotherapy: Theory, Research \& Practice 1979;16(3):252-260. [doi: 10.1037/h0085885]

14. Olthuis JV, Watt MC, Bailey K, Hayden JA, Stewart SH. Therapist-supported Internet cognitive behavioural therapy for anxiety disorders in adults. Cochrane Database Syst Rev 2015 Mar 05(3):CD011565. [doi: 10.1002/14651858.CD011565] [Medline: 25742186]

15. Carlbring P, Andersson G, Cuijpers P, Riper H, Hedman-Lagerlöf E. Internet-based vs. face-to-face cognitive behavior therapy for psychiatric and somatic disorders: an updated systematic review and meta-analysis. Cogn Behav Ther 2018 Jan;47(1):1-18. [doi: 10.1080/16506073.2017.1401115] [Medline: 29215315]

16. Storch EA, Caporino NE, Morgan JR, Lewin AB, Rojas A, Brauer L, et al. Preliminary investigation of web-camera delivered cognitive-behavioral therapy for youth with obsessive-compulsive disorder. Psychiatry Res 2011 Oct 30;189(3):407-412. [doi: 10.1016/j.psychres.2011.05.047] [Medline: 21684018]

17. Vogel PA, Solem S, Hagen K, Moen EM, Launes G, Håland ÅT, et al. A pilot randomized controlled trial of videoconference-assisted treatment for obsessive-compulsive disorder. Behav Res Ther 2014 Dec;63:162-168. [doi: 10.1016/j.brat.2014.10.007] [Medline: 25461792]

18. Bouchard S, Paquin B, Payeur R, Allard M, Rivard V, Fournier T, et al. Delivering cognitive-behavior therapy for panic disorder with agoraphobia in videoconference. Telemed J E Health 2004;10(1):13-25. [doi: 10.1089/153056204773644535] [Medline: 15104911]

19. Matsumoto K, Sutoh C, Asano K, Seki Y, Urao Y, Yokoo M, et al. Internet-Based Cognitive Behavioral Therapy With Real-Time Therapist Support via Videoconference for Patients With Obsessive-Compulsive Disorder, Panic Disorder, and Social Anxiety Disorder: Pilot Single-Arm Trial. J Med Internet Res 2018 Dec 17;20(12):e12091 [FREE Full text] [doi: 10.2196/12091] [Medline: $\underline{30559094]}$

20. Kim JI, Yun J, Park H, Park S, Ahn Y, Lee H, et al. A Mobile Videoconference-Based Intervention on Stress Reduction and Resilience Enhancement in Employees: Randomized Controlled Trial. J Med Internet Res 2018 Oct 22;20(10):e10760 [FREE Full text] [doi: 10.2196/10760] [Medline: 30348630]

21. Rees C, Stone S. Therapeutic Alliance in Face-to-Face Versus Videoconferenced Psychotherapy. Professional Psychology: Research and Practice 2005 Dec;36(6):649-653 [FREE Full text] [doi: 10.1037/0735-7028.36.6.649]

22. Simpson S, Reid C. Therapeutic alliance in videoconferencing psychotherapy: a review. Aust J Rural Health 2014 Dec;22(6):280-299 [FREE Full text] [doi: 10.1111/ajr.12149] [Medline: 25495622] 
23. Goodman WK, Price LH, Rasmussen SA, Mazure C, Fleischmann RL, Hill CL, et al. The Yale-Brown Obsessive Compulsive Scale. I. Development, use, and reliability. Arch Gen Psychiatry 1989 Nov;46(11):1006-1011. [doi: 10.1001/archpsyc.1989.01810110048007] [Medline: 2684084]

24. Houck PR, Spiegel DA, Shear MK, Rucci P. Reliability of the self-report version of the panic disorder severity scale. Depress Anxiety 2002;15(4):183-185. [doi: 10.1002/da.10049] [Medline: 12112724]

25. Liebowitz MR. Social phobia. Mod Probl Pharmacopsychiatry 1987;22:141-173. [doi: 10.1159/000414022] [Medline: 2885745]

26. Spitzer RL, Kroenke K, Williams JB. Validation and utility of a self-report version of PRIME-MD: the PHQ primary care study. Primary Care Evaluation of Mental Disorders. Patient Health Questionnaire. JAMA 1999 Nov 10;282(18):1737-1744. [doi: 10.1001/jama.282.18.1737] [Medline: 10568646]

27. Spitzer RL, Kroenke K, Williams JBW, Löwe B. A brief measure for assessing generalized anxiety disorder: the GAD-7. Arch Intern Med 2006 May 22;166(10):1092-1097. [doi: 10.1001/archinte.166.10.1092] [Medline: 16717171]

28. Hair J, Black W, Babin B, Anderson R. Multivariate data analysis (7th ed). Upper Saddle River, New Jersey: Pearson Education International; 2010.

29. Heinrich Heine. Heinrich Heine Universität Düsseldorf. G*Power: Statistical Power Analyses for Windows and Mac URL: http://www.psychologie.hhu.de/arbeitsgruppen/allgemeine-psychologie-und-arbeitspsychologie/gpower.html [accessed 2019-09-06]

30. Paxling B, Lundgren S, Norman A, Almlöv J, Carlbring P, Cuijpers P, et al. Therapist behaviours in internet-delivered cognitive behaviour therapy: analyses of e-mail correspondence in the treatment of generalized anxiety disorder. Behav Cogn Psychother 2013 May;41(3):280-289. [doi: 10.1017/S1352465812000240] [Medline: 22717145]

31. Webb CA, Rosso IM, Rauch SL. Internet-Based Cognitive-Behavioral Therapy for Depression: Current Progress and Future Directions. Harv Rev Psychiatry 2017;25(3):114-122 [FREE Full text] [doi: 10.1097/HRP.0000000000000139] [Medline: $\underline{28475503}$ ]

32. Young JE, Beck AT. Beck Institute Cognitive Therapy Workshop. 1980 Aug. Cognitive Therapy Scale URL: https://www. beckinstitute.org/wp-content/uploads/2015/10/CTRS-12-2011_portrait-Cognitive-Therapy-Rating-Scale-1.pdf [accessed 2019-11-08]

33. Vallis TM, Shaw BF, Dobson KS. The Cognitive Therapy Scale: Psychometric properties. Journal of Consulting and Clinical Psychology 1986;54(3):381-385. [doi: 10.1037//0022-006x.54.3.381]

\author{
Abbreviations \\ CBT: cognitive behavioral therapy \\ GAD-7: Generalized Anxiety Disorder-7 scale \\ LSAS: Liebowitz Social Anxiety Scale \\ OCD: obsessive-compulsive disorder \\ PD: panic disorder \\ PDSS: Panic Disorder Severity Scale \\ PHQ-9: Patient Health Questionnaire-9 \\ SAD: social anxiety disorder \\ VIF: variance inflation factor \\ WAI: Working Alliance Inventory \\ WAI-SF: Working Alliance Inventory-Short Form \\ Y-BOCS: Yale-Brown Obsessive-Compulsive Scale
}

Edited by $G$ Eysenbach; submitted 03.08.19; peer-reviewed by K Mathiasen, R Bipeta; comments to author 28.08.19; revised version
received 14.09.19; accepted 23.09.19; published 15.11 .19
Please cite as:
Matsumoto K, Yoshida T, Hamatani S, Sutoh C, Hirano Y, Shimizu E
Prognosis Prediction Using Therapeutic Agreement of Video Conference-Delivered Cognitive Behavioral Therapy: Retrospective
Secondary Analysis of a Single-Arm Pilot Trial
JMIR Ment Health 2019;6(11):e15747
URL: $\underline{\text { http://mental.jmir.org/2019/11/e15747/ }}$
doi: $\underline{10.2196 / 15747}$
PMID: $\underline{31730037}$ 
(CKazuki Matsumoto, Tokiko Yoshida, Sayo Hamatani, Chihiro Sutoh, Yoshiyuki Hirano, Eiji Shimizu. Originally published in JMIR Mental Health (http://mental.jmir.org), 15.11.2019. This is an open-access article distributed under the terms of the Creative Commons Attribution License (https://creativecommons.org/licenses/by/4.0/), which permits unrestricted use, distribution, and reproduction in any medium, provided the original work, first published in JMIR Mental Health, is properly cited. The complete bibliographic information, a link to the original publication on http://mental.jmir.org/, as well as this copyright and license information must be included. 